\title{
Neoplasia Endócrina Múltipla Tipo 2 - Manejo Diagnóstico e Terapêutico
}

\author{
Frederico F.R. Maia \\ Hamilton J. Júnior \\ Levimar R. Araújo
}

\begin{abstract}
RESUMO
É relatado o caso de paciente de 26 anos que apresentou sinais e sintomas compativeis com hipertireoidismo, encaminhado para propedêutica endocrinológica. Após 3 meses de evolução, o paciente apresentou hipertensão arterial sistêmica grave. Diante de um paciente jovem, sem história familiar de hipertensão e ausência de outras co-morbidades, foi aventada a hipótese de hipertensão endócrina, e, ainda que rara, neoplasia endócrina múltipla tipo 2. A propedêutica solicitada demonstrou a presença de feocromocitoma bilateral associado a carcinoma medular de tireóide e adenoma de paratireóide. O diagnóstico precoce permitiu a realização do tratamento adequado com evolução favorável do quadro. Os autores discutem as condutas diagnósticas e terapêuticas na neoplasia endócrina múltipla tipo 2. Objetiva-se atualizar, orientar e esclarecer dúvidas dos profissionais a respeito desses fatores. (Arq Bras Endocrinol Metab 2002;46/5:606-610)
\end{abstract}

Descritores: Neoplasia endócrina múltipla tipo 2; Diagnóstico; Tratamento

\section{ABSTRACT}

\section{Multiple Endocrine Neoplasia Type 2 - Diagnostic and Therapeutic Management.}

This 26-years-old male presented with signs and symptoms of hyperthyroidism and was submitted to an endocrine evaluation. After 3 mo, the patient developed severe systemic hypertension. There was no family history of hypertension or other diseases. Endocrine hypertension and a rare syndrome of multiple endocrine neoplasia (MEN) type 2 were diagnosed. The evaluation disclosed the presence of bilateral pheochromocytoma, medullary thyroid carcinoma and parathyroid adenoma. The early diagnosis led to specific treatment and a favorable evolution in this case. Diagnostic and therapeutic management of MEN type 2 are discussed. This study aimed to update, guide and answer some questions of professionals regarding this factors. (Arq Bras Endocrinol Metab 2002;46/5:606-610)

Keywords: Multiple endocrine neoplasia type 2; Diagnosis; Treatment

$\mathrm{O}$ S PRIMEIROS RELATOS SOBRE A NEOPLASIA endócrina múltipla tipo 2 (MEN-2) datam de 1959, descritas por Sipple, que verificou a presença de feocromocitoma, carcinoma medular de tireóide (CMT) e hiperparatireoidismo primário (HPTP) em um mesmo paciente (l). É um quadro crônico, relativamente raro, determinado por uma herança autossômica dominante, ocorrendo na forma esporádica em pequena parte dos casos (1).

A MEN-2 subdivide-se em três síndromes: MEN-2 A, MEN-2B e o carcinoma medular de tireóide familiar. Acomete homens e mulheres em proporções semelhantes, já tendo sido descrita em todas as idades, com incidência estimada em 1 para cada 30.000 indivíduos.
Recebido em 15/01/02

Revisado em 09/04/02

Aceito em 28/06/02 
A MEN-2A consiste na associação de CMT, feocromocitoma e HPTP, na maior parte dos casos. Estima-se em 50 anos a expectativa de vida no portador de MEN 2A (2). A MEN-2B, caracteriza-se pela presença de neuromas mucosos em $100 \%$ dos casos, CMT, hábito marfanóide e feocromocitoma. O HPTP é incomum nessa síndrome (3).

A presença de um caso na família exige investigação diagnóstica nos demais parentes, na busca de se estabelecer um diagnóstico o mais precocemente possível e instituir o tratamento profilático, reduzindo as taxas de morbi-mortalidade nessa população (3).

Apresentamos um caso de um paciente encaminhado ao endocrinologista para propedêutica de "hipertireoidismo" que evoluiu com sinais e sintomas compatíveis com MEN-2. Objetiva-se alertar a classe médica da importância do diagnóstico precoce dessa síndrome, discutindo-se as condutas propedêuticas e terapêuticas nesses casos.

\section{RELATO DE CASO}

HGM, masculino, 26 anos, natural e procedente de Belo Horizonte, encaminhado para avaliação endocrinológica com diagnóstico presuntivo de "hipertireoidismo" e "hipertensão arterial sistêmica (HAS)" em maio de 1998.

O paciente encontrava-se previamente hígido há cerca de 10 meses, quando iniciou com quadro de taquicardia, tremores finos, perda progressiva de peso, acompanhados de episódios de cefaléia temporal pela manhã. Em dezembro de 1997, os sintomas se exacerbaram, com piora gradativa do quadro, agravados ainda com o aparecimento de HAS grave. Nessa ocasião, procurou o clínico geral, sendo medicado com Nifedipina $10 \mathrm{mg} /$ dia e solicitada avaliação endocrinológica.

$\mathrm{Na}$ primeira consulta, o paciente mostrava-se muito ansioso, adinâmico, com grande labilidade emocional, queixando cefaléia intensa, associada a palpitações e tremores de extremidades que chegavam a despertá-lo durante a noite. Estava em uso apenas de Nifedipina. História prévia de correção cirúrgica de hérnia inguinal, sem outras co-morbidades associadas. Revelou história familiar positiva para diabetes e doença tireoideana.

Ao exame, apresentava-se ativo, fácies atípica, corado, hidratado, com rubor facial discreto e mãos quentes. O exame do aparelho cardiovascular demonstrou pressão arterial (PA) em decúbito de $180 \mathrm{x}$ $100 \mathrm{mmHg}$ com freqüência cardíaca (FC) de $85 \mathrm{bpm} \mathrm{e}$
PA em ortostatismo de $110 \times 70 \mathrm{mmHg}$ com FC de $100 \mathrm{bpm}$. O exame específico da tireóide revelou aumento difuso da glândula $( \pm 60 \mathrm{~g}$; VR: $30 \mathrm{~g})$, de superfície regular, indolor e sem nodulações palpáveis. Cadeia ganglionar cervical sem alterações.

Em se tratando de paciente jovem, caucasiano, com quadro de HAS de início súbito, hipotensão postural, sem história familiar de hipertensão e na ausência de outras co-morbidades, foi aventada a hipótese de hipertensão endócrina, e, ainda que rara, neoplasia endócrina múltipla tipo 2 .

A conduta inicial consistiu da análise laboratorial da função tireoideana, dosagens de anticorpo antitireoperoxidase (anti-TPO), glicemia, hemograma e análise de catecolaminas, metanefrinas e cortisol livre em urina de 24 horas. Os resultados revelaram tireóide normofuncionante com TSH de 2,59mU/L (VR: 0,35,0 ); T4 livre de $1,22 \mathrm{ng} / \mathrm{ml}$ (VR: 0,8-2,0), anti-TPO negativo (14UI/ml; VR: <15), com glicemia de jejum de $129 \mathrm{mg} / \mathrm{dl}$ (VR: $<110 \mathrm{mg} / \mathrm{dl}$ ) e cortisol livre (46,6mg/24h; VR: 10-90) em níveis fisiológicos. A análise de urina de 24 horas mostrou níveis elevados de epinefrina $(76,6 u \mathrm{~g} / \mathrm{ml}$; VR: 1-20), norepinefrina $(120,2 u \mathrm{~g} / \mathrm{ml}$; VR: $15-80)$ e normetanefrinas $(0,49 \mathrm{mg} / 24 \mathrm{~h}$; VR: $<0,4 \mathrm{l})$, sem alterações de dopamina e metanefrinas.

Nessa ocasião, foi afastada a hipótese de tireotoxicose e reforçada a possibilidade de hipertensão endócrina, provavelmente feocromocitoma. Foi iniciada terapia farmacológica com Prazosina $2 \mathrm{mg}$ /dia e solicitada nova propedêutica: MIBG (metaiodo-benzilguanidina), níveis séricos de cálcio total, fósforo, magnésio, calcitonina e paratormônio (PTH) intacto, além de ultra-sonografia (US) cervical e raio X de tórax.

Os novos exames revelaram níveis séricos elevados de calcitonina $(2.295 \mathrm{pg} / \mathrm{ml}$; VR: $<50)$, e valores de PTH $(35 \mathrm{pg} / \mathrm{ml}$; VR: 10-65), cálcio total $(9,2 \mathrm{mg} / \mathrm{dL}$; VR: 8,5-10,4), magnésio e fósforo dentro dos padrões fisiológicos. As dosagens de PTH e calcitonina foram realizadas pelas técnicas de quimioluminescência (Kit DPC) e radioimunoensaio (Kit DPC), respectivamente. O MIBG demonstrou hipercaptação difusa do radiotraçador em ambas as adrenais e região parieto-occipital esquerda, sugestivo de feocromocitoma associado a um processo metastático em calota craniana. A US cervical evidenciou lobos tireoideanos assimétricos, alteração textural difusa, com nodulação hipoecóica adjacente em pólo inferior do lobo direito, sugestivo de adenoma de paratireóide. Raio X de tórax sem alterações.

Mediante os dados clínicos, a presença de calcitonina sérica elevada evidenciando a possibilidade de 
CMT, associada a feocromocitoma bilateral com metástase em calota craniana e adenoma de paratireóide, foi estabelecido o diagnóstico de MEN-2A. Nesse caso, foi registrado adenoma de paratireóide ainda sem hiperparatireoidismo.

Foi realizada tomografia computadorizada de abdome em junho de 1998 que demonstrou massas adrenais bilaterais, com cerca de $9 \mathrm{~cm}$ à direita e $8 \mathrm{~cm}$ à esquerda. Com fins acadêmicos, foi solicitada monitorização ambulatorial da pressão arterial (MAPA) que registrou picos hipertensivos durante todo o exame, sobretudo pela manhã, compatível com feocromocitoma.

A conduta subseqüente consistiu de correção da sintomatologia adrenérgica com Prazosina $4 \mathrm{mg} /$ dia seguida de adrenalectomia bilateral em agosto de 1998. Não houve necessidade do uso de beta-bloqueadores nessa ocasião. O pré-operatório imediato foi realizado em unidade de terapia intensiva (UTI). O paciente foi submetido a rígido controle dos níveis pressóricos e à monitorização invasiva com catéter de Swan-Ganz para aferição e controle adequados da volemia. A evolução pós-operatória foi satisfatória, recebendo alta normotenso e em uso de $5 \mathrm{mg}$ de Prednisona. O exame anátomopatológico confirmou o diagnóstico prévio de feocromocitoma bilateral.

Após três meses, o paciente foi novamente submetido a tratamento cirúrgico, sendo realizada exérese de tireóide e paratireóide inferior direita, nessa ocasião. Apresentou boa evolução no pós-operatório, recebendo alta em uso de Prednisona $5 \mathrm{mg} /$ dia e Levotiroxina $125 \mathrm{mcg} /$ dia. O exame anátomo-patológico confirmou o diagnóstico de CMT e adenoma de paratireóide.

Nas consultas subseqüentes, o paciente apresentava-se bem disposto, assintomático, porém mantinha ainda níveis séricos elevados de calcitonina (cerca de $350 \mathrm{pg} / \mathrm{ml}$; VR: $<50$ ). Na possibilidade de processo metastático, foi solicitada TC de encéfalo, tórax e abdome. Não foi detectado nenhum ponto de metástase nos exames. Optou-se, então, pela realização de um tireograma, que evidenciou a presença de $10 \mathrm{~g}$ de tecido tireoideano normocaptante remanescente, demonstrando o provável foco de produção de calcitonina.

Em março de 2000, realizou-se a extirpação total do resquício de tireóide, evoluindo com exacerbação do hipotireoidismo, sem demais intercorrências.

Atualmente, o paciente apresenta-se assintomático, normotenso, casou-se e encontra-se trabalhando normalmente. Está em uso domiciliar de Levotiroxina $200 \mathrm{mcg} /$ dia e Prednisona $7,5 \mathrm{mg} /$ dia. Os níveis de calcitonina séricos permanecem discretamente elevados (cerca de $90 \mathrm{pg} / \mathrm{ml}$ ).

Quanto à metástase de feocromocitoma em calota craniana, optou-se pela conduta conservadora através de acompanhamento clínico e por métodos de imagem, uma vez que o paciente encontra-se normotenso e assintomático.

Os familiares do paciente foram orientados da necessidade e importância do rastreamento por métodos bioquímicos e genéticos para MEN-2A, como forma de se estabelecer o diagnóstico precoce e instituir o tratamento profilático. Devido a certas dificuldades e desinteresse dos mesmos, o estudo dos familiares do paciente não pôde ser realizado. Os mesmos comunicaram a decisão de não realizar o rastreamento para MEN-2A via correspondência convencional, cientes dos riscos de aparecimento futuro da síndrome.

\section{DISCUSSÃO}

Os primeiros registros de vários tumores descritos em um mesmo paciente são de Erdheim (1903) em que descreveu um paciente com acromegalia e quatro paratireóides aumentadas (2).

$\mathrm{O}$ aparecimento dos tumores na MEN-2A estão relacionados a mutações em nível de cromossoma 10 , no braço longo $(10 \mathrm{q} 11.2)$, em região pericentromérica. O gene envolvido nesse processo é o proto-oncogene RET. A mutação nesse gene está presente em 95\% dos casos de MEN-2A (4). Na presença de quadro clássico com feocromocitoma, CMT e tumor de paratireóide, o códon mais acometido do proto-oncogene RET é o 634 (exon 11). Já nos casos de MEN-2B, a alteração ocorre predominantemente no códon 918 (exon 15) do protooncogene RET.

Klein e cols. (2001) realizaram a análise genética de 51 indivíduos com risco de CMT e 14 com história familiar de MEN-2A. Em 9 (13,8\%) casos foram detectadas mutações em códon 634 do proto-oncongene RET. Concluíram que o estudo genético de pacientes com risco de CMT e/ou MEN-2A é fator importante no diagnóstico precoce, prognóstico e tratamento da doença (5). Em casos avançados, como no caso descrito, tal análise não interfere no prognóstico da doença (5).

As manifestações iniciais da MEN-2A são decorrentes do CMT na grande maioria dos casos. Cerca de 10 a $30 \%$ dos casos de CMT estão associados a MEN-2A (5). O feocromocitoma está presente em $40-50 \%$ dos casos. Em geral, a lesão é bilateral, be- 
nigna e precedida por uma hiperplasia da glândula acometida. No caso em questão, a lesão era de provável caráter maligno, já havendo a presença de metástase quando do diagnóstico.

Algumas formas menos comuns encontram-se descritas na literatura, como a associação com doença de Hirschsprung e líquen amiloidótico cutâneo, que representam formas variantes da MEN-2A. Tewari e cols. (2001) relataram o primeiro caso de MEN-2A durante a gravidez (6). Um estudo nos Estados Unidos da América (EUA) verificou a associação de mutação do proto-oncogene RET (códon 634), MEN-2A e agenesia renal unilateral (7).

O diagnóstico da MEN-2A deve ser estabelecido o mais cedo possível. A suspeita clínica acompanhada de testes bioquímicos, de imagem e análise do proto-oncogene RET, seguidos da terapêutica cirúrgica estão relacionados com redução da mortalidade causada pela doença (8). No caso descrito não foi realizada a avaliação genética do paciente, uma vez que o diagnóstico foi clínico e laboratorial. A análise genética do paciente não alteraria as condutas referentes ao caso, além de promover aumento de custos, maior ansiedade do paciente e atraso do tratamento cirúrgico.

No referido caso, a presença de HAS de início súbito, em paciente jovem, leucoderma, sem antecedentes de doença hipertensiva na família, fez suspeitar de hipertensão secundária. Diante da possibilidade de feocromocitoma foi realizada propedêutica para MEN-2A, através de dosagens séricas de calcitonina, cálcio total, fósforo e catecolaminas e metanefrinas urinárias. A presença de níveis elevados de calcitonina sérica e de catecolaminas e normetanefrinas em urina de 24 horas evidenciaram quadro de CMT e feocromocitoma, respectivamente. A US cervical revelou quadro compatível com adenoma de paratireóide.

O método de escolha para avaliação do feocromocitoma consiste na cintilografia com MIBG. Esse método também vem sendo usado na análise da glândula paratireóide, apresentando sensibilidade de $94 \%$ para adenoma simples dessa glândula (8).

Quanto ao tratamento, a literatura considera que o CMT deve ser abordado cirurgicamente com tireoidectomia total associado à paratireoidectomia subtotal (9). Outra alternativa consiste na tireoidectomia total associada à paratireoidectomia total com implante de uma porção de paratireóide no antebraço. Nesse caso, não foi realizada terapia complementar por radioiodo após tireoidectomia, uma vez que não há consenso na literatura para uso da mesma.
Na presença de feocromocitoma, a adrenalectomia total deve preceder qualquer outra intervenção cirúrgica, devido ao risco de pico hipertensivo fatal durante a manipulação da glândula no ato operatório (9). O tratamento cirúrgico deve ser acompanhado de limpeza ganglionar sistemática, de acordo com cada caso, conforme preconiza a literatura (10).

Em relação à metástase de feocromocitoma, a conduta pode ser cirúrgica ou clínica. A abordagem cirúrgica é preconizada nos casos sintomáticos, consistindo de ressecção da porção metastática da calota craniana, seguida de irradiação dos resquícios com doses médias de MIBG ( $15 \mathrm{mCi})$. Já a conduta clínica consiste na irradiação maciça com altas doses de MIBG $(100 \mathrm{mCi})$. A eficácia da radioterapia nesses casos é questionável, segundo a literatura. Com isso, optamos pelo tratamento conservador, uma vez que o paciente encontrava-se totalmente assintomático após seis meses de acompanhamento.

Atualmente, o objetivo primordial é o estabelecimento de diagnóstico cada vez mais precoce em parentes de primeiro grau do indivíduo com MEN2A. O rastreamento em familiares consiste de análise bianual de cálcio sérico, realização de teste de pentagastrina anualmente, dosagens de catecolaminas e metanefrinas urinárias e análise do padrão genético do indivíduo. A busca de mutação no gene RET deve ser realizada em duas etapas, sendo uma no período neonatal e outra na primeira infância. A ausência de mutação nessa ocasião estabelece que o indivíduo apresenta a mesma possibilidade de desenvolver uma MEN-2 que a população geral (10).

O tratamento preventivo em parentes com risco de MEN-2 influencia diretamente na sobrevida desses pacientes. Wallin e cols. (2001) apresentaram os resultados de 20 pacientes tratados cirurgicamente após detecção de mutação no proto-oncogene RET. A tireoidectomia profilática revelou $9(45 \%)$ casos de CMT e 11 (55\%) de hiperplasia de células C (11).

Apesar de rara em nosso meio, consideramos de grande importância que o clínico esteja familiarizado com as alterações clínicas e laboratoriais na MEN-2A, possibilitando o diagnóstico precoce a fim de se instituir o tratamento em tempo hábil. É imperioso suspeitar de MEN-2A em casos de hipertensão aguda súbita, na presença de feocromocitoma, CMT ou hiperparatireoidismo supostamente isolados.

Deve-se aventar a hipótese de MEN-2 em todo parente de primeiro grau do paciente, submetê-los ao rastreamento quando possível e realizar o tratamento profilático, na busca de reduzir a mortalidade e as implicações biopsicossociais dessa síndrome na população. 


\section{REFERÊNCIAS}

1. Canadas V, Vilar L, Moura E, Machado AC, Castellar E. Neoplasias endócrinas múltiplas. In: Vilar L, Castellar $\mathrm{E}$ Moura E, et al. Endocrinologia Clínica 2001:Rio de Janeiro: MEDSl;60:855-69.

2. Friedman E, Boson WL, De Marco L. Neoplasias endócrinas múltiplas. In: Coronho V, ed. Tratado de Endocrinologia e Cirurgia Endócrina. Rio de Janeiro: Guanabara Koogan. 2001;180:1431-6.

3. Wohllk N, Becker P, Youlton R, et al. Germline mutations of the ret proto-oncogene in Chilean patients with hereditary and sporadic medullary thyroid carcinoma. Rev Med Chil 2001;129(7):713-8.

4. Schuringa JJ, Wojtachnio K, Hagens W, Vallenga E, et al. MEN 2A RET-induced cellular transformation by activation of STAT3. Oncogene 2001;20(38):5350-8.

5. Klein I, Esik O, Homolya $\mathrm{V}$, et al. Molecular genetic diagnostic program of multiple endocrine neoplasia type $2 \mathrm{~A}$ and familial medullary thyroid carcinoma syndromes in Hungary. J Endocrinol 2001;170(3):661-6.

6. Tewari KS, Steiger RM, Lam ML, et al. Bilateral pheochromocytoma in pregnancy heralding multiple endocrine neoplasia syndrome IIA. A case report. J Reprod Med 2001;46(4):385-8.
7. Lore F, Talides F, Di Cairano G, Renieri A. Multiple endocrine neoplasia type 2 syndromes may be associated with renal malformations. J Intern Med 2001;250(1):37-42.

8. Rubello D, Saladini $G$, Casara D. The role of scintigraphy with dual tracer and potassium perchlorate (99mTcO4 \& $\mathrm{KLCO} 4 / \mathrm{MIBI}$ ) in primary hyperparathyroidism. Minerva Endocrinol 2001;26(1):13-21.

9. Dotzentrath C, Cupisti K, Goretzki PE, et al. Long-term biochemical results after operative treatment of primary hyperparathyroidism associated with multiple endocrine neoplasia type I and lla: is a more or less extended operation essential? Eur J Surg 2001; 167(3):173-8.

10. Johnston LB, Chew SL, Lowe D, et al. Investigating familial endocrine neoplasia syndrome in children. Horm Res 2001:55(Suppl 1):31-5.

11. Wallin $G$, Bondesson AG, Farnebo LO, et al. Hereditary thyroid cancer can be cured by prophylactic surgery. Lakartidningen 2001;98(25):3024-8.

\section{Endereço para correspondência:}

Frederico Fernandes Ribeiro Maia R. Nunes Vieira, 299 - ap.702 30350-120 Belo Horizonte, MG e.mail: fredfrm@hotmail.com 